\title{
Condensed Products of Boron Combustion in Secondary Chamber
}

\author{
D.P.LIU \& Z.X.XIA
}

Science and Technology on Scramjet Laboratory, National University of Defense Technology, Changsha China

J.X.HU \&L.Y.HUANG

College of Aerospace Science and Engineering, National University of Defense Technology, Changsha China

\begin{abstract}
A experimental setup has been designed for boron particles ignition and combustion. A sampling system with sampling devices has been developed and used to collected condensed combustion products during the tests. The boron combustion products in different test axial locations were sampled and analysed by SEM, EDS and XRD. Agglomeration was formed during heating and combusting and became small while combustion in the secondary chamber. Three products of particles, squamas and protonemas presented orderly.
\end{abstract}

KEYWORD: Boron Combustion; Condensed Production; Secondary Chamber

\section{INTRODUCTION}

Because of boron's high combustion enthalpy boron ignition and combustion processes have been studied for a long time. In earlier researches plate flame burner, laser, plasma and shock wave tube were mainly used to heat boron to ignition temperature. Macek and Semple [1] used plate flame burner and $\mathrm{CO}_{2}$ laser to ignite boron particles, the process of ignition and combustion of $34 \sim 124 \mu \mathrm{m}$ crystalloid boron was researched. Gurevich[2] heated $50 \sim 260 \mu \mathrm{m}$ boron particles and clouds using plasma in order to research the ignition and combustion processes. M. J. Spalding [3] researched the ignition and combustion process of boron particles using shock wave tube. Besides, R.O.Foelsche [4] designed a instrumented high pressure combustion chamber designed for transient combustion studies. High pressure and temperature conditions are established by the explosive reaction (fast deflagration) of nitrogen-diluted hydrogen / oxygen / additive mixtures. In order to get a better understanding of the combustion process and the oxidation of boron in solid rocket ram jet. H.K. Ciezki and B. Schwein [5] developed a sampling system with a water cooled probe for solid fuel based on HTPB with $2 \mu \mathrm{m}$ boron powder added ramjet application and measured in a step combustor. The boronoxide content of the collected condensed phase was analysed. S.W. Abbott and L.D. Smoot 6] used water-cooled probes and boronloaded propellant in the secondary duct of an airaugmented laboratory burner. The combustion products were collected and analysed. In condition of using boron-loaded propellant, the combustion of boron was affected by the other composition in propellant. The combustion process and products was different as the composition of propellant changed. it was worth to measure and investigate combustion and oxidation of element boron in solid rocket ram jet. Jianxin $\mathrm{Hu}$ and Zhixun Xia [7] used boron-based fuel-rich HTPB propellant in the secondary chamber of ducted rocket and investigated the combustion study of the boron particle.

In the present work, a new experimental system has been developed for the investigation of boron combustion characteristics. The experimental system can been used to simulate real solid rocket ram jet but not used solid propellant as in real solid rocket ramjets. Element boron powder was added and heated in the primary section, than secondary burned with air in the secondary chamber. A sampling system was developed for collecting condensed combustion products. The combustion products at different axis locations of the secondary chamber were collected and analyzed. The combustion characteristic of boron was investigated.

\section{EXPERIMENT}

\subsection{Apparatu}

The experimental system developed and used in this study is schematically shown in Fig. 1, which consists of a gas generator and an secondary chamber. The accessorial components are a boron particle supplying device, a condensed combustion 
product sampling device; air, water, oxygen and ethanol supplying systems and a measurement and control system. The experimental system was cooled by water flowing through the channels in the walls in tests.

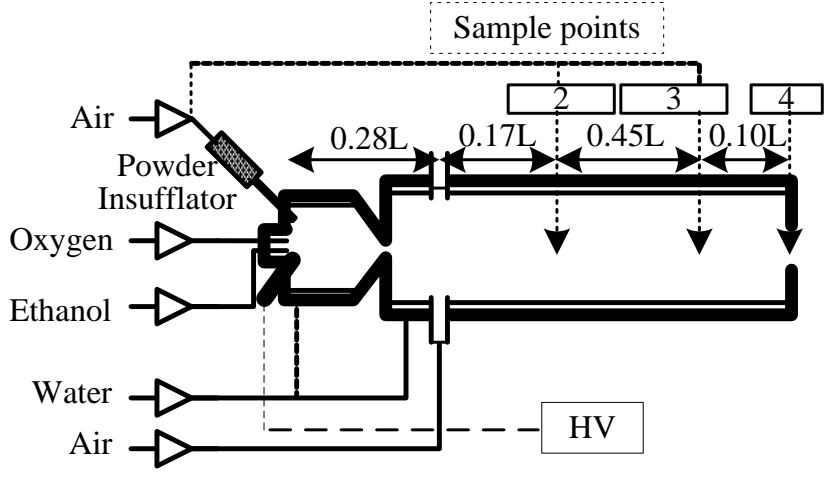

Fig. 1. Schematic diagram of the experimental system

In the gas generator, ethanol was burned with oxygen in low oxygen-fuel ratio producing fuel-rich gas, while boron particles was added and heated. The hot gas with heated particulate boron left to the secondary chamber through a throat. In the secondary chamber, compressed air was added through entrances which were symmetrically located at the top and bottom in tests. The air was mixed and reacted with gaseous and particulate fuels from the gas generator. The mass flow of the oxygen and ethanol could be adjusted by changed the pressure of oxygen and ethanol in supplying systems. And the pressure and temperature in the gas generator and secondary chamber can be changed while the mass flow of the oxygen and ethanol changed. Sampling devices for condensed product collecting were fixed at the top of the secondary chamber, temperature and pressure detectors at the opposite side. The products leave the secondary chamber through a nozzle. The boron powder is transported to the primary heat section by entraining it in the air by means of a boron powder injector. The average boron powder flow rate is determined by weighing the powder reservoir before and after the test.

\subsection{Test Program}

The photo of the whole experimental system is shown in Fig. 2.

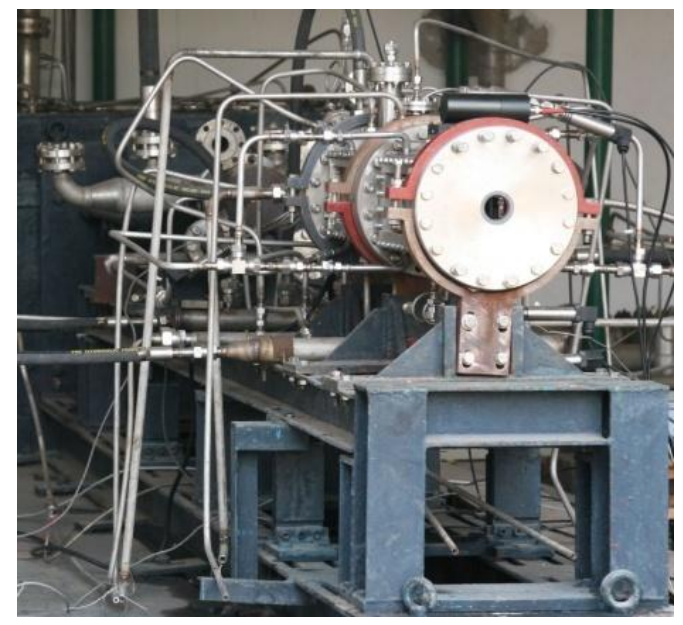

Fig. 2. The photograph of experimental system

There were three groups of tests have been carried out, in which the mass rates of ethanol were kept $120 \mathrm{~g} / \mathrm{s}$ and the mass rates of oxygen were 220 $\mathrm{g} / \mathrm{s}$. Boron used in this research was amorphic boron powder, which was signed as sample 1 and analyzed by physical instrumental as the other samples for comparison. The initial boron particle size was $2 \sim 5 \mu \mathrm{m}$. In order to get reliable data, there were five repetitions for each group of tests. For tests in each group, the test programs kept accordant.

Table 1 Test program

\begin{tabular}{|c|c|c|c|c|c|c|}
\hline Test ID & $\mathrm{O}_{2}(\mathrm{~g} / \mathrm{s})$ & $\mathrm{C}_{2} \mathrm{H}_{6} \mathrm{O}(\mathrm{g} / \mathrm{s})$ & Air for Feeding Boron $(\mathrm{g} / \mathrm{s})$ & Air for Afterburning $(\mathrm{g} / \mathrm{s})$ & Boron $(\mathrm{g} / \mathrm{s})$ & Sampling Point ID \\
\hline 3 & 220 & 120 & 50 & 162 & 4 & $2,3,4$ \\
\hline
\end{tabular}

In the tests, the reservoir was fully filled with boron particles and the valve was connected to the export of the device. Two seconds after the primary heating section was ignited, boron particles were transported into the primary heating section by air. Condensed products in the afterburning section were sampled at the point of 2, 3 and 4 .

\section{RESULTS AND DISCUSSION}

\section{$3.1 X$-ray diffraction examination}

The X-ray diffraction patterns of the raw boron powder (sample 1) and sample 2 to 4 is presented in
Fig. 3. The X-ray diffraction analysis shows that the main crystal phase of the samples is $\mathrm{B}(\mathrm{HO})_{3}$. Because the boron particles used in this research were amorphous, boron was not been detected by XRD. The final product of the reaction of boron and oxygen is $\mathrm{B}_{2} \mathrm{O}_{3}$. But $\mathrm{B}_{2} \mathrm{O}_{3}$ is not steady in air, it absorbs vapor of air quickly and becomes into crystal boric acid. The process could be expressed as $\mathrm{B}_{2} \mathrm{O}_{3}+3 \mathrm{H}_{2} \mathrm{O} \rightarrow 2 \mathrm{~B}(\mathrm{HO})_{3}$. The content of $\mathrm{B}(\mathrm{HO})_{3}$ in the samples represents the content of $\mathrm{B}_{2} \mathrm{O}_{3}$. For the raw boron powder (sample 1), weak diffraction peaks identified to $\mathrm{B}(\mathrm{HO})_{3}$ were obtained, showing that there was a very small quantity of $\mathrm{B}(\mathrm{HO})_{3}$ in the raw boron powder. For sample 2 to 4 , the relative 
intensity of the $\mathrm{B}(\mathrm{HO})_{3}$ peaks of the XRD patterns increased gradually, which indicated the increasing of the content for $\mathrm{B}(\mathrm{HO})_{3}$ in the samples with the increasing of the axial distances from the throat of the primary heating section to the sampling points in the afterburning section.

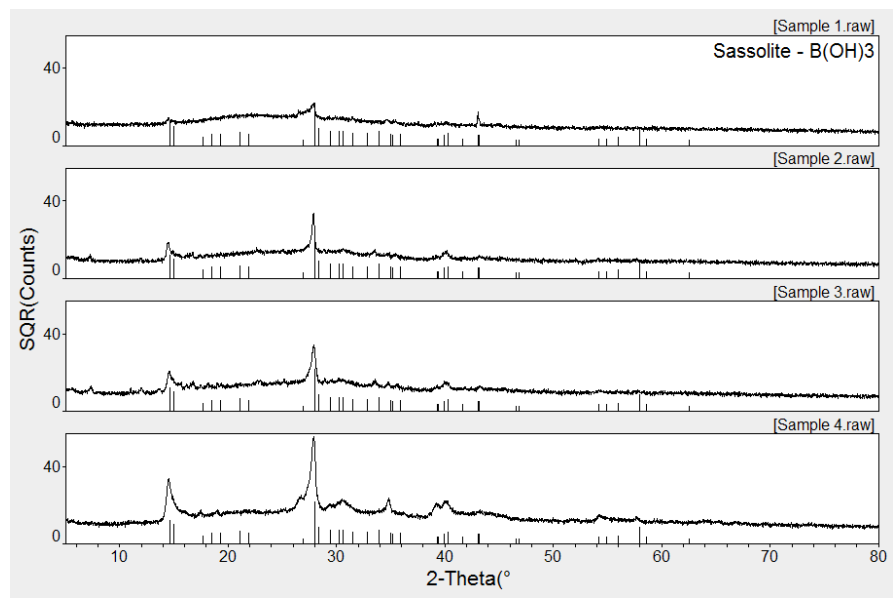

Fig. 3. X-yay diffraction patterns of sample 1 to 4

\subsection{Scan electron microscope (SEM) examination}

The SEM photographs in Fig. 4 show that the boron powder is consist of particles of irregular shape and size $(5000 \times)$. The size of boron particles are between $2 \sim 5 \mu \mathrm{m}$. The samples 2 to 4 are agglomerations. The agglomerations are formed by conglutinated particles of irregular sharpe and size. The size of most of the particles are between $2 \sim 10 \mu \mathrm{m}$, and the size of the largest one is $50 \mu \mathrm{m}$. There are squamas on the surface of the agglomerations in samples 2 to 4 . The sizes of the squamas distribute between $6 \sim 10 \mu \mathrm{m}$. Among the squamas there are fluffy protonemas. The sizes of the squamas distribute between $2 \sim 10 \mu \mathrm{m}$.
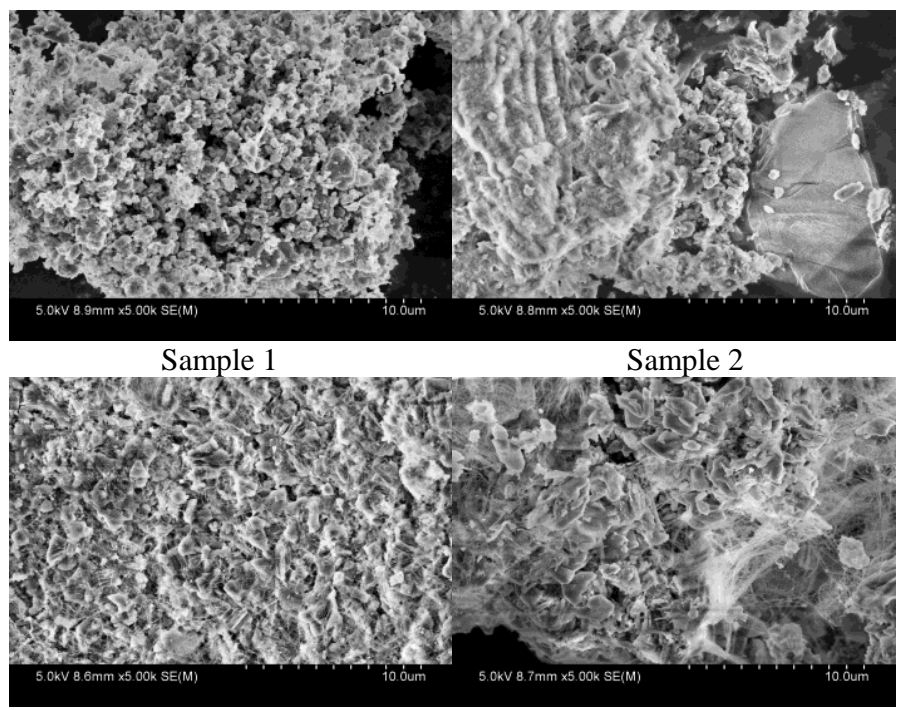

Sample 3

Sample 4

Fig. 4. SEM Photographs of sample 1 to 4

\subsection{Electron diffraction spectra (EDS) examination}

The element weight percentages are shown in Fig. 5. The EDS spectras are shown in Fig. 6. As shown in Fig. 5 and 6, the main elements in the six samples were boron, oxygen and magnesium. The element weight percentage of boron reduced $27.73 \%$ from sample 2 to sample 3 and $2.86 \%$ from sample 3 to sample 4, which indicates that the boron was oxidized a lot in the region between sample point 2 and 3 , but oxidized a little in the region between sample point 3 and the nozzle. In the region between sample point 2 and 3 , gaseous fuel from the primary heating section reacted with oxygen from air added into the secondary chamber. The temperature rose and most of the boron ignited and combusted. As the reaction was going on, the concentration of oxygen decreased and the concentration of $\mathrm{B}_{2} \mathrm{O}_{3}$ increased. So between sampling point 3 and the nozzle where sample 4 was collected, the boron combustion efficiency was depressed.

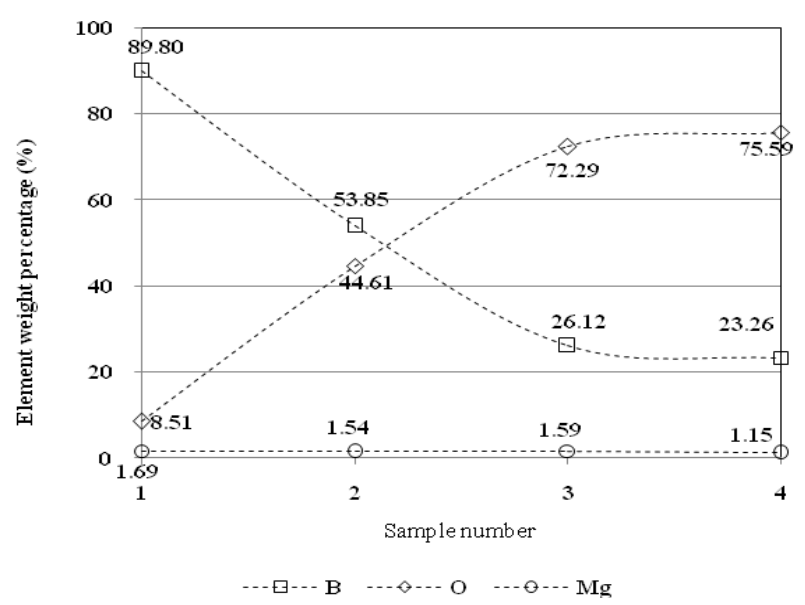

Fig. 4. Element weight and atom percent of Sample 1 to 4
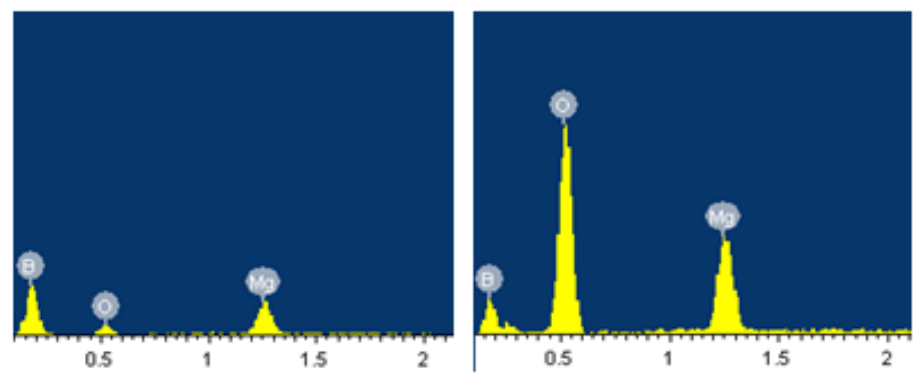

Sample 1
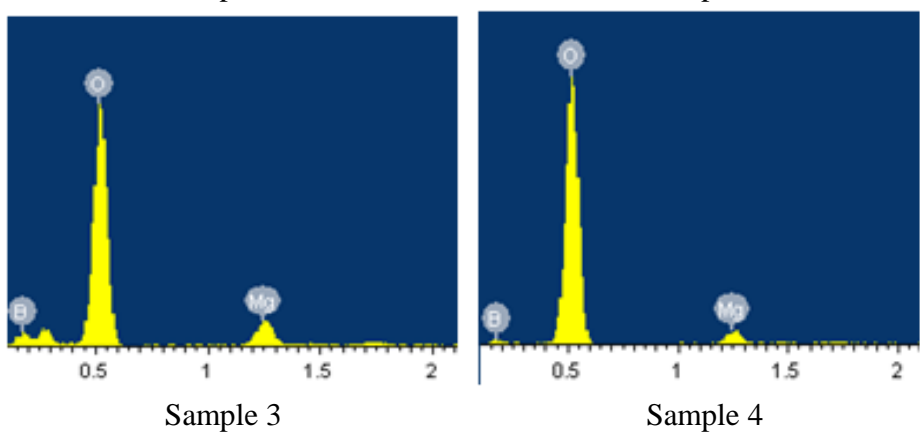

Fig. 5. EDS spectra of Sample 1 to 4 


\section{CONCLUSION}

The main crystal phase of the samples is $\mathrm{B}(\mathrm{HO})_{3}$. For sample 1 to 4 , the content of $\mathrm{B}(\mathrm{HO})_{3}$ increases in the samples with the increasing of the axial distances from the primary heating section to the sampling points in the afterburning section. Agglomerations are formed during reaction in the experimental system. There are squamas and protonemas on the surface of the agglomerations in samples 2 to 4 . The sizes of the squamas distribute between $6 \sim 10 \mu \mathrm{m}$. The sizes of the squamas distribute between $2 \sim 10 \mu$ $\mathrm{m}$. The main elements in the six samples were boron, oxygen and magnesium. Boron was oxidized a lot in the region between sample point 2 and 3 , but oxidized a little in the region between sample point 3 and the nozzle.

\section{REFERENCES}

[1] A.Macek \& J.M.Semple. Combustion of boron particles at atmospheric pressure. $J$ Combustion Science and Technology, 1969(1): 181 191.

[2] M.A.Gurevich, I.M.Kir'yanov, \& E.S.Ozerov, et al. Combustion of Individual Boron Particles. J Combustion, Explosion, and Shock Waves, 1969, 5(2): 217 222.

[3] M. J. Spalding. Boron Particle Ignition and Combustion in a Shock Tube Using Time-Resolved Spectroscopy. D University of Illinois at Urbana-Champaign, 2000.

[4] M. J. Spalding. Ignition and Combustion of Boron Particles in Hydrogen/Oxygen Combustion Products at 30 to 150 Atmospheres. D University of Illinois at UrbanaChampaign, 1998.

[5] H.K. Ciezki \& B. Schwein. Investigation of gaseous and solid reaction products in a step combustion using a watercooled sampling probe. AIAA Paper 1996 : 1-9

[6] S.W. Abbott \& L.D. Smoot. Direct Mixing and Combustion Efficiency Measurement in Ducted, Particle-Laden Jets. $J$ AIAA Journal 1974 Vol 12 No 3 Mach: 275-282

[7] Jianxin hu \& Zhixun xia. Experimental Investigation and Numerical Simulation of Secondary Chamber Flow in SDR. 40th AIAA/ASME/SAE/ASEE Joint Propulsion Conference and Exhibit. AIAA paper 2004-3306, 2004. 